Voix et Images

voixetimages

\title{
La Bête lumineuse ou le gibier imprévu
}

\section{Gilles Thérien}

Volume 8, numéro 1, automne 1982

\section{Madeleine Gagnon}

URI : https://id.erudit.org/iderudit/200376ar

DOI : https://doi.org/10.7202/200376ar

Aller au sommaire du numéro

\section{Éditeur(s)}

Les Presses de l'Université du Québec

\section{ISSN}

0318-9201 (imprimé)

1705-933X (numérique)

Découvrir la revue

Citer ce compte rendu

Thérien, G. (1982). Compte rendu de [ La Bête lumineuse ou le gibier imprévu]. Voix et Images, 8(1), 168-169. https://doi.org/10.7202/200376ar d'utilisation que vous pouvez consulter en ligne.

https://apropos.erudit.org/fr/usagers/politique-dutilisation/ 


\title{
La Bête lumineuse ou le gibier imprévu
}

\author{
par Gilles Thérien, Université du Québec à Montréal
}

Nous sommes habitués à la technique cinématographique de Pierre Perrault: une situation bien définie, un discours tenu par les participants, une vision humaine, passionnée qui est passée par la transformation de l'art et de la pensée du réalisateur. Chaque film est une voix qui s'ajoute à la participation d'orchestre d'une cuvre appelée l'amour du pays. Le sujet de la Bête lumineuse. une partie de chasse, ne devrait pas faire exception et l'on comprend bien comment il devrait s'insérer dans la partition de Perrault. Et puis voila, ce film refuse I'harmonie. II chante son propre solo, grinçant sous la baguette d'un maître devenu subitement silencieux. La Bête lumineuse est un film important, très important par ce qu'il arrive à dire de I'homme.

Un groupe d'hommes, des amis de la région de la Gatineau, se retrouvent pour leur partie de chasse annuelle. Loin de leurs foyers, avec l'aide d'un guide indien, ils vont chasser l'orignal. Un des membres du groupe les accompagne pour la première fois. C'est lui qui servira de détonateur à une action au plus haut point symbolique. La chasse à laquelle on assiste est un rituel précis dont on peut détailler les éléments: le départ du foyer, l'approvisionnement, le voyage, l'installation, la chasse, l'attente, le retour. On a ici l'impression de voir des hommes jouer à Robinson Crusoë. Pendant un certain temps, leurs vies seront offertes à la forêt, à l'absence de frontières. Dépaysés, c'est en eux et entre eux qu'ils referont le monde.

Albert, celui qui est l'intrus dans le groupe, a un physique imposant, du moins en apparence. C'est un adepte de la chasse à l'arc, un grand ami de Bernard et un poète. Sa vision de la chasse est littéraire. Les frémissements de la forêt, l'appel de l'orignal, la vie dans la nature prennent chez lui les détours d'un vocabulaire érotique. II «jouit» de ses fantaisies. Mais, en même temps, c'est un être physiquement faible, peu rompu au travail physique, à l'exercice. La chasse mythique a une contrepartie réelle qu'il aura de la difficulté à supporter. Son corps ne suit pas. Le groupe le remarque et fait d'Albert le souffre-douleur de ce voyage de chasse. Et c'est en ce sens que ce film prend en main son propre discours. 
À l'orignal qu'on chasse à l'extérieur, on ajoute Albert à l'intérieur. On lui tend des pièges, on l'attrape, on le blesse, puis on lui laisse assez de corde pour pouvoir continuer plus longtemps. II faut s'assurer qu'il demeure, tout en se rebiffant. La cruauté se transpose dans ce registre. Tout devient pré-texte. Albert ne sait plus comment interrompre le cercle vicieux, ne cesse de tomber dans de nouveaux panneaux.

Maladroitement, à l'aide d'un poème, il dira, dans une séquence particulièrement lourde, son amour à Bernard. D'aucuns $y$ verront peut-être de l'homosexualité. Ce serait une explication trop facile. Coincé, Albert cherche à établir coûte que coûte une relation avec Bernard qui est en fait le leader naturel de ce petit groupe de chasseurs. Bernard refuse très durement la démarche d'Albert, le laissant aux prises avec sa situation de victime. Qu'Albert cherche à exprimer l'amour ou l'amitié qu'il ressent pour Bernard n'a pas de quoi étonner. Au début du film, on l'a vu, en proie à l'émotion, embrasser son enfant comme pour ancrer cette émotion dans un comportement objectif. C'est ce qu'il cherche à reproduire avec Bernard dont il décrit les qualités en termes de force et de sécurité. Albert ne peut sortir du piège que lui a tendu la cruauté du groupe.

Cette chasse, dont certains épisodes sont très drôles et d'une grande vérité, se termine par une confrontation entre Albert et Bernard. Ce dernier explique calmement, froidement les règles de la chasse. II faut une victime. Albert n'avait qu'à mordre en retour, il n'avait qu'à trouver à son tour une victime, plus victime que lui. Mais Albert est un tendre et un faible. On doute qu'il aura même appris.

Le spectateur, lui, aura assisté à une démonstration de grande violence. Bourreau-victime, prédateur-proie, dominant-dominé, maître-esclave, dans ce microcosme décrit par Pierre Perrault, nous retrouvons l'essentiel de la guerre, de la violence et du meurtre. Ce film devient une sorte d'illustration de la thèse de René Girard sur le bouc émissaire et le caractère primordial du meurtre. Bien sûr, il n'y aura pas ici de morts mais les mécanismes du prédateur alterneront avec les réflexes de la proie. Une image se dégage alors: celle du guide indien qui se lie d'amitié avec la chèvre qui sera, on le suppose, mise à mort. Les deux sont insouciants, résignés et, dans son rôle de victime, Albert est encore moins victime qu'eux. Cette séquence de la chèvre et de I'Indien pointe vers une autre séquence, imaginaire celle-là, de l'orignal, leurré par l'appel, qui fonce vers sa mort.

On comprend le silence de Pierre Perrault. Le rituel ne s'explique pas. II se décrit. II est performance. On le regarde comme on regarde la nature nous découvrir ses merveilles et ses cruautés. Avant le pays, il y a la vie. 